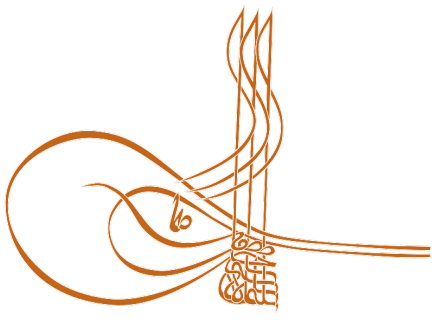

www.turkishstudies.net/language
Turkish Studies - Language and Literature

eISSN: $2667-5641$

Research Article / Araștırma Makalesi

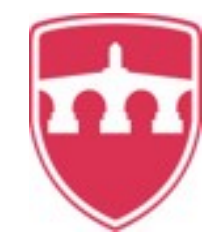

INTERNATIONAL

BALKAN

UNIVERSITY

Sponsored by IBU

\title{
Çağatayca Sıra Dışı Bir Hâl Eki Kullanımı*
}

Usage of an Extraordinary Case Suffixes in Chaghatay

\author{
Feyzi Çimen **
}

\begin{abstract}
The usage of case suffixes instead of each other has been an evident situation since the Old Turkish within the history of Turkish language. Even though it is hard to conclude these usages for certain. The possible reasons of uncertainity can be listed as; the relativity of the structure and function (to relate and make connection between verbs and nouns with different functions), influence of foreign languages, reflecting the features of local language to the literary work by the subscriber, formation types of suffixes and shortening of the suffixes. One can encounter unique usage of case suffixes which were not encountered before in diverse texts and dialect collations. The cases that are accepted as a standard today, a case category in these text styles may be observed. These styles are also important in order to understand the category of cases. The late period Kelile and Dimne translation of Chaghatay that was copied in 1882 contains an extraordinary usage of case suffix. In this text the usage of accusative instead of genitive and vice versa. Thus the equivalance can be derived as: accusative $=$ accusative; accusative $=$ genetive; genetive $=$ genetive; genetive $=$ accusative. In this article, it will be investigated that if this type of usage of the suffix is alternately or a grammar incident because of the non-absolution of the suffix's function. The examples of these suffixes appeared hundreds of times in a vast volume which were investigated and this grammatical incident's occurrence will be tried to be linked to cause and effect relation by taking the general Chaghatay grammatical rules into consideration.
\end{abstract}

Structured Abstract: The usage of case suffixes instead of each other has been an evidential situation since the Old Turkish within the history of the Turkish language. One can encounter unique usage of case suffixes that were not encountered before in diverse texts and dialect collations. These styles are also important to understand the category of cases. The late period Kelile and Dimne translation of Chaghatay language which was copied in 1882 contain an extraordinary usage of case suffix. In this text the usage of accusative instead of genitive and vice versa. Thus the equivalence can be derived as: accusative $=$ accusative; accusative $=$ genetive; genetive $=$ genetive; genetive $=$ accusative. The usage of case suffixes and suffixes instead of each other has attracted the attention of researchers and literature about the subject was created as a thesis, article, book, etc...

\footnotetext{
* Bu makale, Trakya Üniversitesi, Tekirdağ Namık Kemal Üniversitesi, Marmara Üniversitesi, Turkish Studies Dergisi, Uluslararası Balkan Üniversitesi iş birliğiyle 27-30 Haziran 2019 tarihleri arasında Üsküp'te, düzenlenen Uluslararası Sosyal Bilimler Kongresi V (INCSOS-Üsküp-www.incsos.org)'de sunulan bildirinin genişletilmiş şeklidir.

** Dr.. Öğr. Üyesi, İstinye Üniversitesi, Fen-Edebiyat Fakültesi, Türk Dili ve Edebiyatı Bölümü Asst. Prof. Dr. Istinye University, Faculty of Science and Letters, Department of Turkish Language and Literature ORCID 0000-0002-3734-7257

fcimen@istinye.edu.tr

Cite as/ Atıf: Çimen, F. (2020). Çağatayca sıra dışı bir hâl eki kullanımı, Turkish Studies - Social, 15(1), 107-120. https://dx.doi.org/10.29228/TurkishStudies.39442

Received/Geliş: 23 October/Ekim 2019

Accepted/Kabul: 25 February/Şubat 2020

Copyright (C) INTAC LTD, Turkey
} 
- $\quad$ general Turkish literature when we classify the different usage of case suffixes instead of each other in the texts written in different volumes and locations, a usage mentioned before was not observed. Extraordinary usage is:

\section{The usage of genitive instead of accusative $[+\mathrm{NI} \tilde{\mathbf{N}}=+\mathrm{NI}]$}

- $\quad$ andaķ kim ol öyleriniñ birbiridin pest bülend irmes (10-3,4)

- Humāyūn-fāl Huceste-rāydın bu sözniñ éşitti irse (11a-2)

- $\quad$ Rāy bu sözlerniñ işitti irse tamur-1 keremi hareketke (17b-8)

- Ve kiçeniñ tañ atğunça Serendibg̉a barmaķnı endīşesi bilen ötkerdi (23b-8)

- $\quad$ bu sözniñ işitmedüñ kim (21b-1)

The usage of genitive instead of dative $[+\mathrm{NI} \tilde{\mathrm{N}}=+\mathrm{GA}]$

- $\quad$ ol tedbīrniñ siyāset dirler (14a-1)

- $\quad$ Şenzebe aydı ki cengniñ men başlamas-men (108b-14)

The usage of accusative genitive instead of genitive $[+\mathrm{NI}=+\mathrm{N} \dot{\mathrm{N}}]$

- $\quad$ ehl-i bātınlarnı dimāğları mu'attar bolġay (3b-5)

- $\quad$ ve olarnı biri Kelīle ve Dimne kitābı turur (3b-11)

In Chaghatay, the below table can be observed as examples of genitive usage $[+\mathrm{nI} y,+\mathrm{In}, \varnothing]$ and accusative usage $[\mathrm{nI},+\mathrm{n},+\mathrm{I}, \varnothing]$ in exemplary texts.

\begin{tabular}{|l|l|}
\hline (Category of Case suffixes) & (Case suffixes used instead) \\
\hline Genitive $+\mathrm{nI},++\mathrm{In}, \varnothing$ & $\begin{array}{l}\text { Accusative }[+\mathrm{nI}] \\
\text { Dative }[+\mathrm{GA}]\end{array}$ \\
\hline Accusative $+\mathrm{nI},+\mathrm{n},+\mathrm{I}, \varnothing$ & \\
Genitive $)[+\mathrm{nI}]$
\end{tabular}

As it can be understood from the table and the examples, the studies on the usage of accusative instead of genitive are known; the usage of genitive instead of accusative was not observed. Even though it is hard to set a rule based on the usage and determine an absolute usage it is plausible to comment:

It is essential to remember that the grammatical rules can be overrun by the speakers. The language studies are constructed upon the written texts with unchangeable and static grammatical rules. However, one should not rule out the oral form that is open to influence and changes. Especially, this is a significant aspect while writing language texts. Mixed language texts are the best examples. Thus, it is a possibility to find traces of features of oral language in written language.

One should also take the author's initiative into consideration while writing the non-standard language usages. The ethnicity, education, neighbourhood are decisive elements. The local dialect collations' reflections to the text are observed often. Today, the usage of the Turkish language in Balkans, Iraq, Iran and Cyprus constitutes the best examples of the situation mentioned.

Grammar categories are constant and unchangeable, but on the other hand, they are prone to constant change and development. The transformation of + GA a dative to ablative+DIn +Dan is an example. Especially, accusative and genitive share similarities in both function and form. It is possible to perceive the short form of genitive + In as $+n 1$ because of metathesis. Because the letters are the same. The transformation of nasal " $n$ " to normal " $n$ " is well-known. In the same form, two suffixes state a noun phrase. Genitive generally completes the meaning of the noun and accusative's reflecting the meaning of the noun to verbal noun can be considered as a noun phrase. This makes it possible to use the genitive instead of accusative and vice versa. As a matter of fact, the examples listed above rationalizes this possibility.

The alternative usage of a grammar category suffix's function's not becoming absolute which is called alternative suffixes should also be taken into consideration. A wrong usage which is labelled as because of non-standard usage in contemporary Turkey Turkish can be compensated and standardized in Modern Turkish. 
The speakers' common tendencies regarding the form and type of relations among words constructed with or without suffixes are the reflection on the texts. In addition, the choice of suffix usage and meanings installed to the word determines the verb ... and verb regime.

When we unite all these aspects no matter what the reason is; the usage styles of accusative $=$ accusative, accusative $=$ genitive; genitive $=$ genitive, genitive $=$ accusative will become an instrument for new perspectives. The new texts that contain such usages will help us to determine more precisely.

Keywords: Chaghatay Turkish, Case Suffixes, Alternate Usage Of Case Suffixes, Accusative, Genetive.

Öz: İsim hâl eklerinin birbirinin yerine kullanılması, Türk dili tarihi içinde Eski Türkçeden beri bilinen bir durumdur. Bu kullanımları kesin bir sonuca bağlamak zor olsa da şekil ve işlev olarak hâl eklerinin birbirine yakın olması (çeşitli fonksiyonlarla isimlerle diğer kelime türleri arasında münasebet kurmak gibi), mahallî dil özelliklerinin müstensih tarafından esere yansıtılması, eklerin oluşma biçimleri, ek kısalması gibi muhtemel sebepler ilk akla gelenlerdir. Farklı farklı metinlerde ve ağız derlemelerinde daha önce tesadüf edilmeyen hâl eki kullanımlarına rastlanmaktadır. Bugün standart olarak kabul ettiğimiz bir hâl kategorisi için bu tarz metinlerde farklı kullanımlar görülebilmektedir. Bu biçimler hâl kategorisinin anlaşılması adına çok önemlidir. 1882 yılında istinsah edilen geç dönem Çağatayca bir Kelile ve Dimne tercümesinde sıra dışı bir hâl eki kullanımı vardır. Bu eserde Çağataycada yaygın bir kullanım olan akkuzatif ekinin genitif ekinin yerine kullanılmasının yanında tersi olarak genitif ekinin de akkuzatif ekinin yerine kullanıldı̆̆ı görülmektedir. Böylece akkuzatif=akkuzatif, akkuzatif=genitif; genitif=genitif, genitif=akkuzatif denkliği ortaya çıkmıştır. $\mathrm{Bu}$ makalede bu kullanımın bireysel bir müstensih tercihi mi, yoksa bir ekin fonksiyonunun kesinleşmemesinden kaynaklanan nöbetleşe kullanım mı (veya ek nöbetleşmesi) başka bir gramer olayı mı olduğu hususu irdelenecektir. 156212 kelimelik hacimli bir metin olan söz konusu eserde yüzlerce defa geçen bu eklerin örnekleri incelenerek ve genel Çağatayca gramerleri göz önünde bulundurularak bu gramer olayının bir sebep ve sonuca bağlanmasına çalışılacaktır.

Anahtar Kelimeler: Çağatay Türkçesi, Hâl Ekleri, Hâl Eklerinin Birbirinin Yerine Kullanılması, Akkuzatif, Genitif.

\section{Giriş}

Hâl ekleri isimler ile isim soylu kelimeler; isimler ile fiiller arasında çok değişik görev ve fonksiyonda münasebet kuran çekim ekleridir. Hâl eklerinin adlandırılması ve adedi hususunda araştırmacılar arasında ihtilaf olsa da hâl ekleri tüm Türk lehçelerinde benzer ilişki biçimiyle benzer eklerle kurulur. Bununla beraber farklı lehçelerde veya ölçünlü bir dilin ağızlarında hâl eklerinin yapı ve fonksiyonunda değişik kullanımlar göze çarpar. Bu standart dışı kullanımlar birçok araştırmaya konu olmuştur. Farklı farklı metinlerde ve ağız derlemelerinde daha önce tesadüf edilmeyen hâl eki kullanımları, hâl kategorisinin anlaşılması adına çok önemlidir. İsim hâl eklerinin birbirinin yerine kullanılması, Türk dili tarihi içinde Eski Türkçeden beri bilinen bir durumdur. Bu kullanımları kesin bir sonuca bağlamak zor olsa da şekil ve işlev olarak hâl eklerinin birbirine yakın olması (çeşitli fonksiyonlarla isimleri fiillere bağlamak gibi), yan ve üst katman etkisi, mahallî dil özelliklerinin müstensih tarafından esere yansıtılması, eklerin oluşma biçimleri, ek nöbetleşmesi gibi muhtemel sebepler ilk akla gelenlerdir.

Bu makalede biz de Türk dili tarihinde daha önce tesadüf etmediğimiz sıra dışı bir hâl eki kullanımı üzerinde duracağız. Çağataycada yaygın bir kullanım olan akkuzatif ekinin genitif ekinin yerine kullanılmasının yanında, tersi olarak, genitif ekinin de akkuzatif ekinin işlevinde kullanıldığı görülmektedir. Böylece akkuzatif=akkuzatif, akkuzatif=genitif; genitif=genitif, genitif=akkuzatif denkliği ortaya çıkmıştır.

Konuya girmeden bu araştırmaya kaynak teşkil eden eser hakkında bilgi vermek yerinde olacaktır. Sıra dışı hâl eki kullanımının görüldüğü eser Çağatayca bir Kelile ve Dimne tercümesidir. 1882 yılında istinsah edilen eser geç dönem Çağatayca bir nesir (nesir ağırlıklı nazım, nesir karışık) 
metnidir. Eserin tam adı Āsāru'l-İmāmiyye'dir (Çağatayca bir Kelile ve Dimne tercümesi). ${ }^{1}$ Özbekistan'ın başkenti Taşkent'te Fenler Akademisi Ebu Rayhan Biruni Şarkşinaslık Enstitüsü Yazma Eserler Bölümü P11307'de korunmaktadır. Eser 17. yüzyılın son çeyreğinde doğmuş ve 18. yüzyılın başlarında Kaşgar'da yaşayan Molla Muhammed Timur tarafindan kaleme alınmış Kelile ve Dimne metninin istinsahıdır. Eser kahverengi deri bir ciltle kaplanmış olup vişne renginde meşin bir sırtla takviye edilmiştir. $2+367+2$ varaktır. Sayfa boyları $22 \times 36 \mathrm{~cm}$ olup nestalik hatla yazılmıştır. Konu başlıkları, noktalar, çizgiler ve istişhat için zikredilen Arapça ibareler kırmızı mürekkeple yazılmıştır. Her sayfada 15 satır bulunmaktadır. Temmet tārih bir miñ üç yüz senesinde uşbu nüsha-i mu’teber safer ayını törtünçi küni penşenbe kéçesi mihrbān-ı huudāvendī bu faḳīr ḥaḳīr şikesteni ḳolıda itmāmg̀a yétti. Safer ayının 4. gecesi 1300 tarihi Miladi 15 Aralık 1882 tarihine tekabül etmektedir ki nüsha eserin telifinden aşağı yukarı yüz yıl sonra istinsah edilmiştir. Müstensih "fakir, hakir" sıfatlarıyla ismini geçiştirmiştir.

156212 kelimelik hacimli bir metin olan söz konusu eserde onlarca defa geçen genitif ekinin akkuzatif fonksiyonunda kullanıldığ örnekler incelenerek ve genel Çağatayca gramerler göz önünde bulundurularak bu kullanımın bireysel bir müstensih tercihi mi, yoksa bir ekin fonksiyonunun kesinleşmemesinden kaynaklanan nöbetleşe kullanım mı (veya ek nöbetleşmesi) veya başka bir gramer olayı mı olduğu irdelenecektir.

Hâl ekleri ve eklerin birbirlerinin yerine kullanılması birçok araştırmacının dikkatini çekmiş ve konuyla alakalı çok sayıda tez, makale, kitap vb. araştırmacılar tarafindan kaleme alınmıştır. Bu araştırmalar, hâl kategorisini oluşturan eklerin oluşumu, hâl eklerinin standartlaşması, hâl eklerinin fonksiyonları, hâl eklerinin birbirlerinin yerine kullanılması vb. konuları kapsar.

Genel Türk dilinde değişik zamanlarda, farklı hacimlerde ve birbirinden uzak mekânlarda kaleme alınan eserlerdeki hâl eklerinin birbirlerinin yerine kullanımlarını kabaca tasnif edip tabloya döktüğümüzde karşımıza şöyle bir manzara çıkar. ${ }^{2}$

\section{Birbirileri Yerine Kullanılan Hâl Ekleri}

\section{Doğu Türkçesinde (Harezm Sahasında) ${ }^{3}$ Hâl Eklerinin Birbilerinin Yerine Kullanımı}

\begin{tabular}{|c|c|}
\hline Hâl Kategorisi & Yerine Kullanılan Hâl Ekleri \\
\hline Yükleme & $\begin{array}{l}+ \text { GA } \\
+ \text { nIñ, } 1 \tilde{n} \\
+ \text { DIn } \\
+ \text { DA }\end{array}$ \\
\hline Yönelme & $\begin{array}{l}+ \text { n1, +n, +I } \\
+ \text { DA } \\
+ \text { DIn } \\
+ \text { nIñ, iñ } \\
+\mathrm{n},+1 \mathrm{~A} \\
+ \text { çA }\end{array}$ \\
\hline Bulunma & $\begin{array}{l}+\mathrm{DIn} \\
+\mathrm{GA} \\
\end{array}$ \\
\hline
\end{tabular}

\footnotetext{
${ }^{1}$ Eserin diğer nüshaları ve ayrıntılı bilgi için bk. Feyzi Çimen, “Çağatayca Kelile ve Dimne Tercümeleri”, Türk Kültürü Incelemeleri Dergisi, S. 33, s. 237-260, İstanbul, 2015.

2 Burada birçok araştırmacının sonuçları tablo olarak sunulmuştur. Söz konusu eserlerde aynı gramer kategorisi için birbirinden farklı terim kullanılmış olduğundan kaynaklara referans için kaynakta yer alan terimler korunmuştur. Bu tarz hâl eki kullanımları özel veya standart dışı kullanımlar olduğu için çalışmalara konu olan biçimler sunulmuştur. Burada yer almayan buna benzer şekiller, zikredilmeyen bir başka lehçede de olması muhtemeldir. Araştırmalar devam ettikçe farklı biçimlerin görülmesi olasıdır.

${ }^{3}$ Ayrıntılı bilgi için bk. Lütfiye Güvenç, “Harezm Türkçesinde İsim Hâl Eklerinin Görev Değişiklikleri”, VI. Uluslararası Türk Dili Kurultayı Bildirileri 20-25 Ekim 2008, C.II, s. 2081, Ankara, 2013.
} 


\begin{tabular}{|l|l|}
\hline & $+\mathrm{n},+1 \mathrm{~A}$ \\
\hline \multirow{3}{*}{ Ayrılma } & $+\mathrm{DA}$ \\
& $+\mathrm{n},+\mathrm{n},+\mathrm{I}$ \\
& $+\mathrm{GA}$ \\
& $+\mathrm{n},+1 \mathrm{~A}$ \\
\hline \multirow{2}{*}{ Eşitlik } & $+\mathrm{DIn}$ \\
\hline
\end{tabular}

Eski Anadolu Türkçesinde Hâl Eklerinin Birbilerinin Yerine Kullanımı ${ }^{4}$

\begin{tabular}{|c|c|}
\hline Hâl Kategorisi & Yerine Kullanılan Hâl Ekleri \\
\hline Yalın & $\begin{array}{l}+(\mathrm{y}) \mathrm{I} \\
+\mathrm{dA} \\
+\mathrm{dAn} \\
+(\mathrm{I}) \mathrm{n} \\
+\mathrm{CA}\end{array}$ \\
\hline Belirtme $+(y) I,+n I$ & $\begin{array}{l}\text { Yalın (Ø) } \\
+(\mathrm{y}) \mathrm{A} \\
+\mathrm{dAn}\end{array}$ \\
\hline Yönelme + (y)A, +GA & $\begin{array}{l}\text { Yalin }(\varnothing) \\
+(\mathrm{y}) \mathrm{I} \\
+\mathrm{dA} \\
+\mathrm{dAn}\end{array}$ \\
\hline Bulunma $+d A$ & $\begin{array}{l}\text { Yalın (Ø) } \\
+(\mathrm{y}) \mathrm{I} \\
+(\mathrm{y}) \mathrm{A} \\
+\mathrm{dAn} \\
+(\mathrm{I}) \mathrm{n} \\
+\mathrm{CA} \\
\end{array}$ \\
\hline Ayrılma + dAn & $\begin{array}{l}\text { Yalin }(\varnothing) \\
+(\mathrm{y}) \mathrm{A} \\
+\mathrm{dA} \\
+\mathrm{CA}\end{array}$ \\
\hline Vasita $+(\mathrm{I}) \mathrm{n},+1 \mathrm{~A}$, birle & $\begin{array}{l}\text { Yalın }(\varnothing) \\
+(\mathrm{y}) \mathrm{I} \\
+(\mathrm{y}) \mathrm{A} \\
+\mathrm{dA} \\
+\mathrm{dAn}\end{array}$ \\
\hline Eşitlik $+\mathrm{CA}$ & $\begin{array}{l}\text { Yalin }(\varnothing) \\
+(\mathrm{y}) \mathrm{A} \\
+\mathrm{dA} \\
+\mathrm{dAn}\end{array}$ \\
\hline
\end{tabular}

\section{Anadolu Ağızlarındaki Hâl Eklerinin Birbilerinin Yerine Kullanımı ${ }^{5}$}

\begin{tabular}{|l|l|}
\hline Hâl Kategorisi & Yerine Kullanllan Hâl Ekleri \\
\hline
\end{tabular}

\footnotetext{
${ }^{4}$ Ayrıntılı bilgi için bk. Gürer Gülsevin, Eski Anadolu Türkçesinde Ekler, Türk Dil Kurumu Yayınları, Ankara, 1997.

${ }^{5}$ Ayrıntılı bilgi için bk. Ahmet Buran, Anadolu Ağızlarında İsim Çekim (Hal) Ekleri, Türk Dil Kurumu Yayınları, Ankara, 1996.
} 


\begin{tabular}{|l|l|}
\hline \multirow{3}{*}{ Yalın } & Belirtme \\
& Vasita \\
& Eşitlik \\
\hline \multirow{3}{*}{ Tamlama } & Yalın (Ø) \\
& Belirtme \\
& Yönelme \\
\hline \multirow{3}{*}{ Yönelme } & Yalın (Ø) \\
& Yönelme \\
& Bulunma \\
& Çıma \\
\hline \multirow{3}{*}{ Bulunma } & Yalın (Ø) \\
& Tamlama \\
\hline \multirow{3}{*}{ Çıma } & Belirtme \\
& Bulunma \\
& Çıkma \\
\hline \multirow{2}{*}{ Vasıta } & Yalın (Ø) \\
& Yönelme \\
\hline \multirow{2}{*}{ Eșitlik } & Çıma \\
\hline & Yalın (Ø) \\
& Belirtme \\
& Yönelme \\
& Bulunma \\
\hline & Yönelme \\
& Çıkma \\
\hline & Eşitlik \\
\hline & Vasita \\
\hline
\end{tabular}

Çağdaş Lehçelerdeki Hâl Eklerinin Birbilerinin Yerine Kullanımı ${ }^{6}$

\begin{tabular}{|c|c|c|}
\hline Dil/Lehçe & Hâl Kategorisi & Yerine Kullanılan Hâl Ekleri \\
\hline Uygur & \multirow[b]{2}{*}{ Yalın } & $+\mathrm{I},+\mathrm{DA}$ \\
\hline Gagavuz & & $+\mathrm{A},+\mathrm{DA},+\mathrm{DAn}$ \\
\hline Uygur & \multirow[b]{2}{*}{ İlgi Hâli } & \\
\hline Gagavuz & & $+\mathrm{A}$ \\
\hline Uygur & \multirow[b]{2}{*}{ Yükleme Hâli } & $\varnothing,+\mathrm{GA},+\mathrm{DA}$ \\
\hline Gagavuz & & $+\mathrm{A}$ \\
\hline Uygur & \multirow[b]{2}{*}{ Yönelme Hâli } & $+\mathrm{I},+\mathrm{DA}$ \\
\hline Gagavuz & & $\emptyset,+\mathrm{I},+\mathrm{DA},+\mathrm{DAn}$ \\
\hline Uygur & \multirow[b]{2}{*}{ Bulunma Hâli } & $\varnothing,+\operatorname{din}$ \\
\hline Gagavuz & & $+\operatorname{In}(\mathrm{nIn}, \mathrm{An}),+\mathrm{DAn}$ \\
\hline Uygur & \multirow[b]{2}{*}{ Çıkma Hâli } & $+\mathrm{DA}$ \\
\hline Gagavuz & & $+\mathrm{A},+\mathrm{I},+\mathrm{DA}$ \\
\hline Uygur & \multirow[b]{2}{*}{ Vasıta Hâli } & $+\mathrm{GA},+\mathrm{DA}$ \\
\hline Gagavuz & & $+\mathrm{A},+\mathrm{DA},+\mathrm{DAn}$ \\
\hline
\end{tabular}

Çağatayca'da İlgi Hâli (Genitif) İle Yükleme Hâli (Akkuzatif) Ekinin Kullanımı Çağatayca'da İlgi Hâli (Genitif) Ekinin Kullanımı

Çağatayca ilgi hâli eki +nıñ, +niñ, +nuñ, +nüñ'dür. Bazen +nIñ yerine bazı ağızlarda +nI kullanılır. Kısalmış genitif eki şeklen + nI akkuzatif eki ile aynı olduğu için 3. Şahıs iyelik eklerinden

${ }^{6}$ Ayrıntılı bilgi için bk. Nevzat Özkan, “Uygur Türkçesi ve Gagavuz Türkçesinde Hal Ekleri Görev Değişikliği”, Tuncer Gülensoy Armağanı, s. 299-319, Kayseri, 1996. 
sonra + n biçimiyle + nIñ yerine kullanılır. Men, sen, gibi şahıs zamirlerinden sonra ve $n$ ile biten kelimelerden sonra ilgi ekinin +iñ biçiminde kullanıldığı görülür.

Genitif fonksiyon olarak sahiplik, aitlik, yakın münasebet (Köñüm-nüñ kuşı), bir olma veya yapmanın failini (Kamil mürşid-niñ irş̧adi), bir hareketin nesnesini (Seniñ Teñriñ-niñ ibadetin kılalıñ) bir parçada bütünü (Hindistan eliniñ köpreki), cevher fiil ile çekime girerek yüklemi (Bu ma'la hocanıñdur) bildirir. ${ }^{7}$ Örneklerde görüldüğü üzere genitif eki çoğu zaman ismi isme; nadiren de ismi fiile (cevher fiile) bağlar. Bu çalışmaya konu olan eserde genitif ekinin kullanım biçimleri şöyledir:

\section{İlgi (Genitif) Hâlinin +niñ Biçimiyle Kullanımı}

anıñ üçün kim $(13 b-7)^{8}$

anıñ birlen berāberlı̣̣ ḳıla'lmaslar (15a-4,5)

özge peyġāmberlerniñ hīç birlerige bu ṣıfatlıg söz kılġan érmes 3a-9)

Biliñ ki lāy bile künniñ yüzin sıvap bolmas (5A-1)

her sözniñ çehresi (3b-6)

ḥaḳiḳat çeşmesiniñ feyżı (4a-11)

ol zemānda Īrān pādşāhlarınıñ sözleri ol til birle irdi (5a-15)

kimniñ fermānı birlen (9b-4)

\section{İlgi (Genitif) Hâlinin +iñ biçimiyle kullanımı}

bu bīşe meniñ şikār-gāhım turur (80a-7)

meniñ sözüm saña ne eser ḳ1ġusidur (26b-8)

Şehā iḳbāl bahtı cānı̃̃ olsun (122a-1) men $(90 \mathrm{a}-8,9)$

men seniñ dék yārnıñ müşkilluḳ (9) bilen ḳolg̉a kiltürüdüm āsānluḳ bilen ḳoldın ipermegey-

\section{İlgi (Genitif) Hâlinin Eksiz Kullanımı}

vahş̄ cān-verler ve çehār-pālar ve ḳuşlar tilleridin türlük hikāyetler ve rivāyetler birle beyān ḳ1lipdurlar (3b-15, 4a-1)

Hindistān pādşāhı ḩizāneside kitābī bar (5a-3)

ol kitāb żamirin éşitip rag̉bet ḳ̂ldı $(5 b-5,6)$

endek sāye tapıp āsāyīş tutḳay-miz tā ki āf-tāb 'anḳası mag̉rib āşiyānesig̉a meyl ḳılg̉ay ve andın soñra biz daġı öz menzilimizġa yanġay-miz $(7 \mathrm{a}-14,15)$

ümīd 'arsası dék vasī' ve tama' meydānı dék kiñrü (8a-7)

Misāfir ve cāy-dārlarnı öz nasībesi birlen horsend ḳıldılar (17b-9,10)

İlgi (Genitif) Hâlinin Yükleme (Akkuzatif) Hâli Fonksiyonunda Kullanımı [+niñ= +ni] andaḳ kim ol öyleriniñ birbiridin pest bülend érmes $(10-3,4)$

\footnotetext{
${ }^{7}$ Buradaki bilgiler János Eckmann, Çă̆atayca el kitabı, çev. Günay Karaağaç, Akçağ Yayınları, Ankara, 2005. s. 6466'dan özetlenmiştir.

8 Örneklerin verildiği metin yazma halinde bulunduğunda örneklerin geçtiği varak ve satır numarası verilmiştir. Örneklerdeki ilk sayı varak numarasını, ikinci sayı satır numarasını belirtmektedir. Eserin özgün biçimi ÖzbekistanTaşkent’te Ebu Reyhan Birüni İsimli Şarkşinaslık Enstitüsü P11307 korunmaktadır.
} 
Humāyūn-fāl Hुuceste-rāydın bu sözniñ éşitti érse (11a-2) $11,12)$

bir kişi heme hünerniñ niçük tamām (12) ḳılıp olar birle ma‘īşet-i meșāliḥin ḳılġusıdur (13a-

ve ammā pād-şāh hüşyār bolup olar garażların gavrig̉a yetse ve küllī cüzvī işlerniñ yahşs teftīş ḳılıp rāstnı yalg̀andın imtiyāz ḳılsa hem dünyā saltanātı bünyādı haleldin hāāī bolur ve hem ăhiretde necāt devleti derecāt rif'atig̉a ulanur (15a-12,13,14,15)

Rāy bu sözlerniñ éşitti érse tamur-1 keremi harareketke (17b-8)

ve kiçeniñ tañ atg்unça Serendibg̉a barmaḳnı endīşesi bilen ötkerdi (23b-8)

tā men hem anıñ ețrāf ve cevābını mülāḥaẓa ḳılayın ve ne tedbīr kim ittifāḳ (8) étkü-miz durur anı̃ ihtiyār eyleyin (24a-7,8)

ya'nī garāib bolmaḳ renc meşaḳḳatg̉a özün salmaḳ ve yār diyārıdın ayrılmaḳ öziniñ otḳa salmaḳdur $(25 b-11,12)$

bu sözniñ işitmedüñ kim (21b-1)

Tileydür-men kim mundın soñ sefer meşaḳkatın defterin oḳumag̉ay-sen kim sefer miḥnetini ot1 kişiniñ büşürür $(26 b-3,4)$

Bāzende ol yahş̧ı menzilniñ pesend éyledi ve anda iḳāmet ḳılmaḳnıñ lāzım bildi. $(27 a-3,4)$

fî’l-ḥāl öziniñ bir ulug taşnı penāhıg̉a aldı (28a-14)

kişiniñ esfel-i sāfilīn pāyesidin a'lā-y1 'illiyyīn derecesig̀a ulandurur. (37a-12,13) $(38 b-11,12)$

ol derende ve cerendeler kim burundın bu bīşeniñ ārzū ḳılur irdiler hemesi aña ḳasd eylediler $(39 b-14,15)$

mundag̉ ıssıg̉da bu miḳdār uzun yolnıñ ḳat' ḳılduk el-ḥamdu'lil-lāh ki işimiz kifāyet taptı ataları yéne aydı ki bu māllarnı̃ tapmaḳda renc tartmadıñılar ḳadrin bilmeseñizler (43b-7)

Üçünçi āhiret sevābınıñ hāsıl ḳılmaḳ ve hudānı raḥmetig̀a öznin vāsıl éylemek (44a-2,3)

Mālnıñ kimniñ üçün ḳıldıñ ḳabūl (44a-5)

vilāyetide pādıșāhī bar irdi kim kām-kār ve ‘ālī miḳdār bes zamāne havādisiniñ körgen (44b-

nāgāh kefş-dūz belā-yı nāgehān dék kélip āvāzınıñ tanuy ḳaldı (69b2)

Ey mihmān dostum nālemniñ éşitip ve derdimniñ bilip ḥālımġa baḳ (70a-1,2)

tā seniñ öz ornumda ḳoyup (70a-5)

yārımġa ‘özrler aytıp seniñ boşatḳay-men (70a-6)

anı̃̃ benddin halās ḳıldı (70a-9)

ustıranı̃̃ kolığa bérdi (71b-7)

belki heme belālarnıñ özimiz özimizge ḳılduḳ (72a-11)

tonımnıñ alıp ḳaçmas irdi (72b-1)

bularnı̃ körüp (75b-15)

her kişi kim ḳılmag̉u işniñ ḳılsa körmegü nemerselerniñ körer. (77a-2) 
Ve bu meselniñ aña kéltürdüm(77a-3)

hemīşe işleri kişiniñ helāk ḳılmak érdi (77b-3)

burunrak yılannıñ öltürürler (80b-4)

seniñ körmedim meger yahş1llk ve hayr bolġay (85a-10)

ve mundaḳ kişi belā girdābıg̉a tüşerdin burun öziniñ ḩalās sāhilig̉a yétkürür (87a-11)

men hem ol balık dék belā kélürin burun bilsem gamımnı̃ yer érdim (88a-14)

Bul sözni men éşittim érse seniñ andın āgāh ḳ1lmaḳḳa kéldim (94b-14,15)

bülbül vāḳı'aların ve olar münāz̧aralarınıñ éş̧itmedüñ bolg̉ay (98b-11)

Ve men saña şefḳatim tolalıkidin bul sözlerniñ dédim (112a-1)

Ḳuş kördi ki sözleriniñ éşitmetmeydürler (112b-4)

anı̃ āşikārā ḳılmaḳ yahş̧ıdur (115b-5)

men bu işniñ yahşı tedbīr birle dürüst ḳıldım $(116 a-5,6)$

anı yüzidin çibinleriniñ uçurur érdi (119b-4)

ve ol dost diyānetin taşlap temürniñ satıp harc ḳılġan érdi $(120 \mathrm{a}-13,14)$

Ol ḩiyānetkārdın bul sözniñ éşitti (120b-2)

Yéseñ biriniñ tapıp ḳoyġıl biriniñ (173a-2)

munçanıñ bildiler ve ne nasihat-gūynıñ sözin ḳulaklarıg่a aldılar $(218 b-2,3)$

bu ḩaberniñ éşittim érse yurtumdın ümīd üzdüm (315a-14)

İlgi (Genitif) Hâlinin Yönelme (Datif) Hâli Fonksiyonunda Kullanımı [+niñ= +ga]

ol tedbīrniñ siyāset dérler (14a-1)

çün kim kimerse bir pād-şāhigia muḳarreb boldı, elbette cem'ī anıñ ḥased yérler ve çün sultān anıñ haḳıda tolaraḳ muḳarreb érkenin kördiler érse hịleler birle aña ziyān yétkürmek ve yoḳ étmaḳge kūşiş ḳ̂lurlar $(20 \mathrm{~b}-12,13,15)$

Şenzebe aydı ki cengniñ men başlamas-men (108b-14)

\section{Yükleme (Akkuzatif) Hâl Eki ve Kullanımı}

Çağatayca akkuzatif hali eki, +nI ekleridir. (köñü̈ñ-ni, ok-nı baş-nı, it-ni, vb.) 3. Şahıs iyelik eklerinden sonra genellikle $+\mathrm{n}$ biçimiyle kısalarak kullanılır. (okı-n (okunu yerine), suyı-n (suyunu yerine) Şiirlerde kafiye gereği $i$ şseklinde de olabilir.

Akkuzatif eki İsmin manasını fiile taşır. Bütün geçişli fiiller akkuzatif ekini alabilir, akkuzatif ekini alan kelime cümlede belirtili nesne olur; akkuzatif eki kullanılmayan yapılardaki nesne belirsiz olur. ${ }^{9}$ Cümlenin yüklemi geçişli olduğu halde akkuzatif eki almayan kullanımlar da Çağatayca'da yaygın olarak görülür.

Bu çalışmaya kaynak teşkil eden Çağatayca metinde akkuzatif ekinin kullanımı şu şekildedir:

\section{Yükleme (Akkuzatif) Hâlinin +nı Biçimiyle Kullanımı}

anda ta'accüb ve ḥikmet hezil ve lehvni ḳatıp (3b-13)

\footnotetext{
${ }_{9}^{9}$ Ayrıntılı için bk. Eckmann, age. s.69-70.
} 
żımnıda reng be-reng fâ 'idelı̣̣ ḥikmet ve nasiḥatlarnı derc bitipdürler (4a-1,2)

anı bildürmeki āsān bolġay (4a-4)

bu kitābnı türlük sibaḳlar birle taṣnīf tapḳanını beyān ḳılur-miz. (4b-5)

ol kitāb nüshasını yahşs hīle birle ḳolg̀a kéltürüp endek fursatda Hind tilidin Behlevī tilig̣a tebdīl ḳıldı $(5 \mathrm{a}-13,14)$

ol Behlevī nüshanı Nūşirvān ḳatığa kéltürdi (5a-15)

yerni tutmaḳka tag̉larnı mıhlar yaratdım ve ba'żı evliyālarnı evtād nām atarlar kim 'ālem olar bereketidin ber-pā turur. $(8 \mathrm{a}-4,5)$

letāfetlik ag̉zıñızlarnı kesāfetlıg nemerselerg̉a mübeddel ḳılmañızlar (10a-9)

Ve ol ‘aselni ag̉zıdın yandurup öyleride cem' ḳ1lı ḳoyarlar(10a-14)

belki fî’l-hāāl tutup anı iki pāre ḳılurlar. (10b-8)

ol bī-pervā yasavullarnı öldürürler(10b-10)

ve heme naḳdıñnı haḳ rıżāsı üçün sadaḳa eyledin (18a-5)

\section{Yükleme (Akkuzatif) Hâlinin +n Biçimiyle Kullanımı}

Ma‘ānī cemālın müşāhede ḳılmaḳ birle zāhir-bīnler közleri münevver (3b-3)

Biliñ ki lāy bile künniñ yüzin sıvap bolmas (5a-1)

Nūşirvān saltanat bināsın ol kitāb mutāla'ası̀ga ḳoydı $(5 b-3,4)$

ol kitāb żamirin éşitip rag̉bet ḳıldı $(5 b-5,6)$

hīleler birle Behlevī nüshasın ḳolg̀a kiltürüp imām Ebū'l-Hasan 'Abbdu'llāh ibni Muḳaffì kim 'asr fāżıllarınıñ kāmili irdi aña buyurdı kim anın tamāmın Behlevī lug̉atdın 'Arabīg̀a kéltürdi $(5 b-6,7,8)$

ḥak ta'ālānı merg̀-zār sahnıdag̉ı 'acāyib masnu'ātların ve mahlūḳātların mute'allıḳ temāşāsın ḳ1ur érdiler. $(8 b-13,14)$

sun'1 ilāhī ḳalemi su yüziniñ safhasın raḳam ḳılıp durur (9a-5)

Pādışāh arular hucūmın kördi érse vezīrdin sordı (9b-2)

ve olar ahvāl ve keyfiyetlerin her kişidin sordum (15b-15) $(16 \mathrm{~b}-7,8)$

zulm ḳarasın bu cihān yüzidin arıtıp irdi ve 'adl çehresin (8) iḥsān közgöside körsetip érdi.

\section{Yükleme (Akkuzatif) Hâlinin +i Biçimiyle Kullanımı}

Seni ten mülkige şāh itti bī-çūn

Teñri meger yarattı seni kim meniñ üçün $(36 b-5,6)$

\section{Yükleme (Akkuzatif) Hâlinin Eksiz Kullanımı}

anı içide bir parça ḥarīr üzre néçe sutre ḥaṭ kördi (20a-1)

ag̉ır genc kördi şād handān bolup (46a-3)

şīr eger tavış̣anan alġan bolsa ol ḥālde ḳulannı körse anı taşlap aña yügürür (53b-8)

her kün yag̀ ve 'asel satar irdi (246a-11) 
'arab bir yarım dinār berdi deryā lebide olturdı nān yemeḳga meşgūl boldı (277b-12)

Yükleme (Akkuzatif) Hâlinin İlgi (Genitif) Hâli Fonksiyonunda Kullanımı [+ni= +niñ]

ehl-i bātınlarnı dimāg̀ları mu'attar bolg̉ay tā her kişi öz ḥavṣalasıg̉a lāyık anıñ bī-nihāyet iḥsānı hॅ̄ānıdın behre-mend bolg̀ay. (3b-4,5)

ve olarnı biri Kelīle ve Dimne kitābı turur kim Hind hükemāları anıñ ḩāṣ țarz birle tertīb berip cāmi‘ 'lı̣ bile ve hikmet-āmīzlıḳ bile yasap durur $(3 \mathrm{~b}-11,12,13)$

Ol kitābnı mütāla'asıġa raġbeti ve meyli bisyār boldı (5a-10)

ve mülāzimlerni her biri bir arı̀ yaḳasıda ārām taptılar. (8b-6)

ḥavādis otunçısını tişesi anıñ şāhlların kesmekga yaḳın yetip durur. (9a-12,13)

ammā bularnı bir pādışāhı bardur (9b-13)

ol dırahtnı tübig̀a bardı ve zamanī tevakḳuf ḳılıp olarnı ordasını ve dergāhını ve olarnıñ barmaḳ kelmaḳlarını ve pādışāhlarıg̉a mülāzimet ve hizmetlerini ve fermān-ber-dārlik ḳılışlarını temāşā eyledi $(11 \mathrm{a}-4,5,6)$

barça halāyıḳnı emvālın özlerig̉a cem‘ ḳılġaylar.(13b-12)

Ki ‘ömr sürmekni huușūlı tapmaḳ érken yahşı at $(15 b-8,9)$

Ve çün pādışāhnı naz̧arı ol 'ārif-i dil-āgāhg̉a tüşti (18b-6)

seniñ ve bizni aramızda burundın dostluk (94b-6)

ér ornıdın ḳopup çerāġnı yandurup hatunını ḳaşıg̉a bardı anı burnınıñ selāmet kördi der-hāā rāst irken dép 'özr-h āhlı̣ tilep ḳol ayaġını yaşıp benddin boşattı ve tövbe ḳıldı ki mundın narı ol pāk-dāmān pārsā huatunnı yaman șıfat birle yād ḳılmagey-men (71a-12,13,14,15)

Üçünçi āḩiret sevābınıñ hāsıl ḳılmaḳ ve ḩudānı raḥmetig̉a öznin vāsıl éylemek (44a-2,3)

uyḳu leşkeri anı dimāğı șaḥnıg̉a toldı érse (18a-2)

Çağatayca ilgi hâli (genitif ) [+nIñ, +Iñ, Ø] eki almış metin örnekleri ile yükleme hâli (akkuzatif) [nI, +n, +I, Ø] eki almış metin örneklerini tablo şeklinde sunarsak karşımıza şöyle bir manzara çıkar:

\begin{tabular}{|l|l|}
\hline Hâl Kategorisi & Yerine Kullanılan Hâl Ekleri \\
\hline & Yükleme (akkuzatif) $[+$ nI $]$ \\
İlgi Hâli (Genitif) + nIñ, + Iñ,$\varnothing$ & Yönelme (datif) $[+\mathrm{GA}]$ \\
\hline Yükleme Hâli (Akkuzatif) + nI, + n, + I, Ø & İlgi hâli (genitif) $[+$ nIñ $]$ \\
\hline
\end{tabular}




\section{Sonuç}

Buraya kadar verdiğimiz tablolarda ve metin örneklerinde hâl eklerinin birbirlerinin yerlerine kullanımlarını gördük. Tablolardan ve örneklerden anlaşılacağı üzere şimdiye kadar yapılan çalışmalarda akkuzatif ekinin genitif eki fonksiyonunda kullanılması durumu bilinirken; genitif ekinin akkuzatif eki fonksiyonunda kullanılması tesadüf edilmeyen bir kullanımdır. $\mathrm{Bu}$ kullanımı kesin bir sonuca bağlamak ve bu örneklerden kesin bir hüküm/kural çıkarmak zor olsa da bazı şeyler söylemek mümkündür:

Gramer kaidelerinin dil konuşurlarının sistemli dil kullanımlarının zapt edilmiş biçimleri olduğu hatırdan çıkarılmamalıdır. Dil çalışmaları nispeten sabit ve değişmez genel kural niteliği taşıyan yazılı metinler üzerine inşa edilir. Ancak, dillerin yazılı ve sabit metinleri yanında değişim ve tesire açık aktüel sözlü/ konuşma kısmını da göz ardı etmemek gerekir. Özellikle dil metinlerinin yazıya geçirilme sürecinde bu husus çok belirleyicidir. Karışık dilli eserler bunun en güzel örneğidir. Dolayısıyla konuşma dili özelliklerinin yazıya aksetmesi çoğu zaman vaki olan bir ihtimaldir.

Standart olmayan dil kullanımlarını yazıya geçiren müellif/yazar tasarrufunu da hesaba katmak gerekir. Metni yazıya aktaran müellif veya müstensihin etnik kimliği, eğitim gördüğü muhit, yaşadığı ve etkilendiği coğrafya belirleyici unsurlardandır. Eseri kaleme alan kişi tarafından mahalli ağız özelliğinin esere yansıtılması Türk dili tarihinde sıklıkla görülen bir durumdur. Bugün Balkanlarda, Irak ve İran'da ve Kıbrıs’ta konuşulan Türkçedeki kullanımlar bu duruma en güzel örneklerdendir.

Gramer kategorileri bir yandan sabit ve değişmezken diğer yandan sürekli bir değişme ve gelişme temayülü gösterir. Datif eki olan + GA'nin + A; ablatif ekinin + DIn +DAn olması gibi. Özellikle akkuzatif ve genitif ekleri hem şekil hem de fonksiyon bakımından benzerlik gösterirler. Genitif ekinin kısalmış şekli olan +Iñ metatez sonucu + nı gibi algılanması akıldan uzak bir ihtimal değildir. Çünkü eki meydana getiren harfler aynıdır. Nazal ñ'nin normal n'ye dönmesi zaten bilinen bir husustur. Aynı şekilde iki ek gramer kategorisi olarak bir tamlama bildirirler. Genitif genellikle ismin manasını tamlar; akkuzatifin ismin manasını fiile taşıması isim-fiil münasebeti bağlamında pekâlâ bir tamlama olarak düşünülebilir. Bu da genitifin akkuzatif; akkuzatifin genitif yerine kullanılmasını mümkün kılar. Nitekim yukarıda sıraladığımız onlarca örnek bu ihtimali akla getirmektedir.

Ek nöbetleşmesi denilen "bir gramer kategorisi ekinin fonksiyonunun kesinleşmemesinden kaynaklanan nöbetleşe kullanımının" da hesaba katılması gerekir. Bugün Türkiye Türkçesinde standart dışı olduğu için "yanlış" olarak ifade ettiğimiz bir kullanım tarihi ve modern Türk dilinde ölçünlü bir biçime tekabül edebilmektedir.

Eklerle ve eksiz biçimde kurulan kelimelerin birbirleriyle olan ilişkisinin şeklini ve niteliğini belirleyen noktalardan biri de dili konuşanların ortak temayüllerin yazıya aksetmesidir. Buna bağlı olarak ekseriyet teşkil eden ek kullanımı tercihi ile kelimeye yüklenen anlamlar fiilin istemini ve rejimini belirler.

Tüm bunları birleştirdiğimiz zaman sebebi her ne olursa olsun farklı kullanım biçimleriyle ortaya koyduğumuz akkuzatif=akkuzatif, akkuzatif=genitif; genitif=genitif, genitif=akkuzatif denkliği hâl kategorisinin anlaşılmasında yeni açılımlara vesile olacaktır. Bu ve bunun gibi kullanımların görüldüğü yeni metinler daha isabetli karar vermemize yardımcı olacaktır. 


\section{Kaynakça}

Akartürk, Salman. (2001). "Türkmen Türkçesinde Hal Eklerinin Birbirinin Yerine Kullanılması," Türklük Bilimi Araştırmalarl $=$ Journal of Turkology Research, S.10: 359-364. Sivas.

Başdaş, Cahit. (2001). "Divanü Lügati't-Türk'teki Şiirlerde İsim Hâl Eklerinin Kullanılışları”, İlmi Araştırmalar, S.11: 29-40, İstanbul.

Bayraktar, Sibel. (1999). "Kutadgu Bilig'de Bulunma Hâli Ekinin Fonksiyonları", Türk Dili Araştırmaları Yıllı̆̆ $\breve{l}$ Belleten [TDAYB Belleten], C.I-II, S.42: 9-25. Ankara.

Boz, Erdoğan. (2007). “Adın Yükleme (Nesne) Durumu ve Tümcenin Nesne Ögesi Üzerine”, Turkish Studies / Türkoloji Araştırmaları, Volume 2/2 Spring: 102-108.

Çimen, Feyzi. (2018). “Özbekçe Hâl Eklerinin Fiillere Bağlanma Durumları”, Turkish Studies International Congress on Social Sciences II (INCSOS 2018 Quds) Volume 13/15, Spring: 467-493.

Çimen, Feyzi. (2015). “Çağatayca Kelile ve Dimne Tercümeleri”, Türk Kültürü İncelemeleri Dergisi, S. 33, s. 237-260, İstanbul.

Demir, İmdat. (2014). "Türkçede Belirtme-Yönelme Hâli Ekleri ve Güneybatı Anadolu Ağızlarındaki Kullanımları”, Sosyal Bilimler Dergisi / Cilt: 16, S. 1: 129-147.

Demirci, Kerim. (2007). "Türkçedeki Hal Eki Nöbetleşmeleri Üzerine”, Karaman Dil-Kültür ve Sanat Dergisi: 126-139, Karaman.

Eckmann, János. (2005). Çă̆atayca el kitabı, çev. Günay Karaağaç, Ankara: Türk Dil Kurumu Yayınları.

Eraslan, Kemal. (2000). "Eski Türkçe'de Yönelme (Dativ) Hâli Ekinin Yapı, Fonksiyon ve İfadeleri”, Türk Dili ve Edebiyatı Dergisi [İstanbul Üniversitesi Edebiyat Fakültesi Türk Dili ve Edebiyatı Dergisi] [TDED], XXIX. Cilt: 7-76, İstanbul.

Gülsevin, Gürer. (1997). Eski Anadolu Türkçesinde Ekler, Ankara: Türk Dil Kurumu Yayınları.

Güvenç, Lütfiye. (2008). "Harezm Türkçesinde İsim Hâl Eklerinin Görev Değişiklikleri”, VI. Uluslararası Türk Dili Kurultayı Bildirileri 20-25 Ekim, C.II: 2073-2084. Ankara: 2013.

Karahan, Leyla. (tarih yok) "Yükleme (Accusative) ve İlgi (Genitive) Hali Ekleri Üzerine Baz1 Düşünceler”,http:/turkoloji.cu.edu.tr/YENI\%20TURK\%20DILI/leyla_karahan_yukleme.p df.

Kelīle ve Dimne, Özbekistan Fenler Akademisi, Ebu Rayhan Birūn̄̄ Şarkşinaslık Enstitüsü, Yazma Eserler Bölümü, P11307, Taşkent, Özbekistan.

Kirişçioğlu, Fatih. (2000). "Kuzey-Doğu Türk Lehçelerinde Hâl Eklerindeki Varyantlaşma, $I V$. Uluslararası Türk Dili Kurultayı Bildirileri II, 24-29 Eylül, C.2: 1065-1068, Ankara: 2007.

Özdemir, Hakan. (2017). "Eski Türkçede İlgi ve Belirtme Durum Ekleri Üzerine" Adlı Makalede Bir Düzenleme, Journal of Turkish Language and Literature, Volume: 3, Issue:2, Spring: 155-168.

Özek, Fatih. ve Sağlam, Bilgit. (2014). "+Dan Çıkma Hâli Ekinin Vasıta ve Bulunma Hâli İşlevi Üzerine", Firat Üniversitesi Sosyal Bilimler Dergisi, Firat University Journal of Social Science, Cilt: 24, Sayı: 2: 13-18, Elâzı̆̆.

Özkan, Abdurrahman. (2011). "Eski Anadolu Türkçesindeki Bazı Fiillerin Hâl Ekli Tamlayıcıları ve Bu Tamlayıcılarda Zaman İçinde Görülen Değişiklikler”, Turkish Studies- International 
Periodical For The Languages, Literature and History of Turkish or Turkic Volume 6/1 Winter: 521-532.

Özkan, Nevzat. (1996). "Uygur Türkçesi ve Gagavuz Türkçesinde Hal Ekleri Görev Değişikliği", Tuncer Gülensoy Armağanı: 299-319, Kayseri.

Özkan, Nevzat. (2001). "Hal Ekleri Kalıplaşmaları ve Sebepleri Üzerinde Bir Değerlendirme”, İlmi Araştırmalar", S.12:.153-165, İstanbul.

Sev, Gülsel. (2007). Tarihi Türk lehçelerinde hâl ekleri, Ankara: Akçağ Yayınları.

Şahin, Erdal. (2003). Tarihi ve çağdaş Türk yazı dillerinde hâl ekleri ve işlevleri. Yayımlanmamış doktora tezi, Marmara Üniversitesi Türkiyat Araştırmaları Enstitüsü, İstanbul.

Tekin, Talat. (2003). “Türkçe İlgi Hâli Ekinin Kökeni Üzerine”, çev. Gökçen Bilgin, Dil Araştırmaları Dergisi, S.13: 157-162, Ankara: 2013.

Yaman, Ertuğrul. (2000). "Özbek Türkçesinde Tamlayıcı-Fiiil İlişkisi ve Bazı Hâl Eklerinin Farklı Kullanılması", IV. Uluslararası Türk Dili Kurultayı Bildirileri II, 24-29 Eylül 2000, C. 2 : 1907-1920, Ankara: 2007. 